\title{
QUEEN'S
UNIVERSITY
BELFAST
}

\section{Silk-inspired polymers and proteins}

Hardy, J. G., \& Scheibel, T. R. (2009). Silk-inspired polymers and proteins. Biochemical Society Transactions, 37(4), 677-681. https://doi.org/10.1042/BST0370677

\author{
Published in: \\ Biochemical Society Transactions
}

Document Version:

Peer reviewed version

Queen's University Belfast - Research Portal:

Link to publication record in Queen's University Belfast Research Portal

Publisher rights

(C) 2009 The Biochemical Society

This research was originally published in Biochemical Society Transactions. Hardy, JG \& Scheibel, 'Silk-inspired polymers and proteins', Biochemical society transactions, 2009; Volume:37, pp 677-681

\section{General rights}

Copyright for the publications made accessible via the Queen's University Belfast Research Portal is retained by the author(s) and / or other copyright owners and it is a condition of accessing these publications that users recognise and abide by the legal requirements associated with these rights.

Take down policy

The Research Portal is Queen's institutional repository that provides access to Queen's research output. Every effort has been made to ensure that content in the Research Portal does not infringe any person's rights, or applicable UK laws. If you discover content in the Research Portal that you believe breaches copyright or violates any law, please contact openaccess@qub.ac.uk. 
Manuscript title: Silk-inspired polymers and proteins.

Number of words: Abstract 76 words. Introduction-Acknowledgements 2527 words.

Authors: John G. Hardy ${ }^{1}$ and Thomas R. Scheibel ${ }^{2}$

Affiliation: Lehrstuhl für Biomaterialien, Universität Bayreuth, Universitätsstraße 30, 95440

Bayreuth, Germany.

1email: john.hardy@bm.uni-bayreuth.de

2email: thomas.scheibel@bm.uni-bayreuth.de

Abstract: The biocompatibility, biodegradability and benign conditions under which natural silk protein fibres (with impressive mechanical properties) are produced represent a biomimetic ideal. This ideal has inspired people in both academia and industry to prepare silk-mimetic polymers and proteins by chemical and/or biotechnological means. This mini-review aims to give an overview of the design principles of such silk-inspired polymers/proteins, their processing into various materials morphologies, their mechanical and biological properties and finally their technical and biomedical applications.

Keywords: silkworm silk, spider silk, silk-inspired, biomimetic materials.

Abbreviations used: Ala, Alanine; Arg, Arginine; Asp, Aspartic acid; E. coli, Escherichia coli; Glu, Glutamic acid; Gly, Glycine; HFIP, Hexafluoroisopropanol; MW, molecular weight; PEG, Poly(ethylene glycol); Pro, Proline; RGD, ArgGlyAsp; Ser, Serine; Val, Valine; TM, Trademark; Wt\%, percent of weight; Xaa, any amino acid. 


\section{Introduction}

Arthropods have evolved to produce a variety of task-specific silk protein-based fibres. Silkworms produce cocoons from silk protein-based fibres as a means of protection during their metamorphosis into moths, and web-weaving spiders produce a number of different silk proteinbased fibres to capture prey (in webs), to protect/preserve their offspring/prey (in cocoons), and as lifelines to escape from predators; and certain silk fibres have mechanical properties superior to Nylon, Kevlar and high-tensile steel. Naturally occurring silkworm and spider silk fibres have been used by humans for millennia for applications as diverse as currency, hunting (bow strings, fishing lines or nets), paper, textiles and wound dressings owing to their mechanical properties and biocompatibility [1-3].

Table 1. Mechanical properties of natural silks and man-made fibres

\begin{tabular}{|c|c|c|c|}
\hline Material & $\begin{array}{c}\text { Tensile strength } \\
\text { (MPa) }\end{array}$ & $\begin{array}{c}\text { Elongation at break } \\
\mathbf{( \% )}\end{array}$ & $\begin{array}{c}\text { Toughness } \\
\mathbf{( M J ~ m}^{\mathbf{3}} \mathbf{)}\end{array}$ \\
\hline Bombyx mori cocoon silk & 600 & 18 & 70 \\
\hline Araneus diadematus lifeline silk & 1100 & 27 & 160 \\
\hline Nylon & 900 & 18 & 80 \\
\hline Kevlar 49TM & 3600 & 2.7 & 50 \\
\hline High-tensile steel & 1500 & 0.8 & 6 \\
\hline
\end{tabular}

Silk fibres are typically composite materials, composed primarily of silk proteins (to which they owe their mechanical properties) and other associated molecules (such as glycoproteins and lipids). Silkworm fibres are composed of 2 microfilaments embedded in a glycoprotein (sericin) coating. The microfilaments comprise a 6:6:1 complex of 3 different proteins: heavy chain fibroin (which is hydrophobic with a molecular weight (MW) of ca. $350 \mathrm{kDa}$ ) that is linked to light chain fibroin (which 
is relatively hydrophilic with a MW of ca. $25 \mathrm{kDa}$ ) via disulfide bonds, and P25 protein ( $\mathrm{MW}$ of 30 $\mathrm{kDa}$ ) that is linked via hydrophobic interactions. A spider's lifeline, in contrast, has a core-shell type structure slightly different to the structure of silkworm silk; the core filament is an inhomogeneously distributed polymer blend of mainly 2 proteins (spidroins) that is coated with glycoproteins and lipids $[1,4]$.

Fibroin

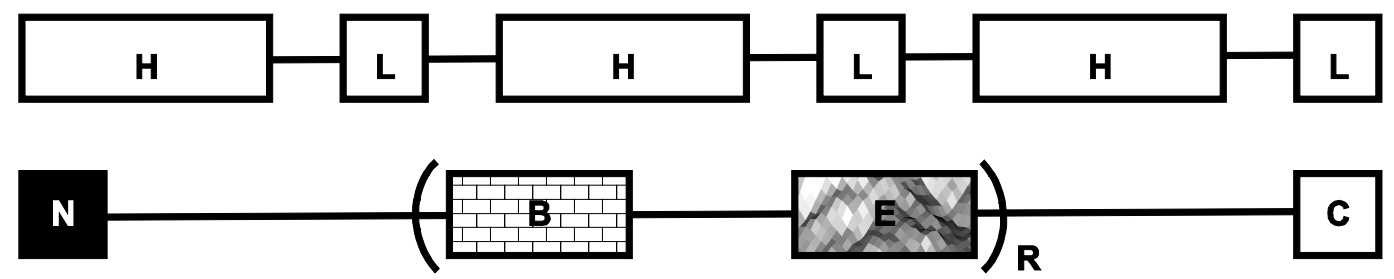

Figure 1. Highly simplified schematic representation of the primary structures of silk proteins: in the case of silkworm fibroin, $\mathrm{H}$ represents the heavy chain fibroin (containing many repeats of the $\beta$-sheet forming GlyAlaGlyAlaGlySer hexapeptide), L represents the light chain fibroin; in the case of spider spidroin, $\mathbf{N}$ represents the amino-terminus non-repetitive amino acid sequence, $\mathrm{B}$ represents the alanine rich blocks of $(\mathrm{Ala})_{n}$ and (GlyAla $)_{n}$ flanking them that are known to form $\beta$ sheet structures, E represents the blocks of (GlyGlyAla) ${ }_{n}$ that form $3_{1}$-helices and/or (GlyProGlyXaaXaa) ${ }_{n}$ that form $\beta$-turn spirals that impart elasticity/flexibility to the proteins, $R$ represents the number of repetitive blocks of $B / E$, and $C$ represents the carboxy-terminus nonrepetitive amino acid sequence.

The natural process of production (known as spinning) for silkworms and spiders is highly complex. Silk proteins are stored within the animal as remarkably highly concentrated protein solutions (up to 50 wt \%) without the occurrence of undesirable aggregation. When necessary, the protein solution can be transported through a duct in which the protein solution is subjected to chemical and mechanical stimuli (such as ion exchange, extraction of water, acidification and elongational flow) that promote protein assembly into fibres. 
The impressive mechanical properties of silkworm and spider silk fibres are due to the fact that they are relatively elastic matrices of protein toughened by anisotropic nanoparticulate inclusions (formed from stacks of $\beta$-sheets). In the case of Bombyx mori silkworm fibroin the GlyAlaGlyAlaGlySer hexapeptide repeat is known to form $\beta$-sheets, whereas the fibroins of Antheraea pernyi and Samia cynthia ricini silkworms and spidroins of spiders are $\beta$-sheet rich due to repetitive stretches of poly(alanine). The toughness of spider silks is greater than that of silkworm silks because the anisotropic $\beta$-sheet inclusions in spider silk are smaller and better aligned with the long axis of the due to the post-spin drawing process carried out by spiders.

Mankind has been able to cultivate Bombyx mori silkworms in captivity and harvest their silk for thousands of years, but attempts to do the same with spiders have proven unsuccessful due to their cannibalistic nature. The biocompatibility, biodegradability and benign conditions under which highperformance fibres are produced have inspired the preparation of silk-mimetic polymers and proteins.

\section{Silk-inspired polymers}

Natural silk fibres can be crudely described as matrices of relatively elastic protein toughened by $\beta$ sheet nanoparticles, formed by the controlled self-assembly of silk proteins under specific chemical/mechanical conditions. Therefore, silk fibres are nanoparticle-reinforced composite materials. Studies of the self-assembly of a number of silk protein inspired copolymers (containing blocks of $\beta$-sheet forming peptides [GlyAla $]_{n}$ or $A\left(a_{n}\right)$ have been reported in the last decade. $\beta$-sheet rich fibres or films have been prepared from: triblock copolymers composed of PEG and either $\left[(\text { AlaGly })_{3}-\right.$ GluGly $_{10}$ or $\left[(\mathrm{AlaGly})_{3}-\mathrm{GluGly}_{20}[5-7]\right.$; multiblock copolymers composed of poly(isoprene) and Alas-spacer-Ala 5 [8]; and brush copolymers prepared from acrylonitrile and silk peptides (derived from the reaction of acryloylchloride with chymotrypsin degraded Bombyx mori fibroin) [9-11]. 
However, the effect of the non-peptidic blocks on the mechanical properties or biodegradability of these materials has not yet been reported.

The Sogah group have reported the most comprehensive studies of silk-inspired polymers. Multiblock copolymers (with MWs between 27 and $40 \mathrm{kDa}$ ) composed of a rigid aromatic spacer (derivatives of phenoxathiin or xanthene) that templated parallel or antiparallel $\beta$-sheet formation of 2 pendant GlyAlaGlyAla tetrapeptides, linked to flexible blocks (of short alkane or ethylene glycol chains). Films cast from formic acid solution were $\beta$-sheet rich but very brittle $[12,13]$. Replacement of the rigid aromatic spacer with a flexible poly(ethylene glycol) (PEG) spacer improved the solubility of the polymers to up to $50 \mathrm{wt} \%$ in trifluoroethanol. Films cast from trifluoroethanol solution had markedly improved mechanical properties (tensile modulus ca. $225 \mathrm{MPa}$, tensile strength ca. 14 MPa, elongation at break ca. 21\%) due the increased flexibility of the PEG matrix [14].

The same group prepared multiblock copolymers (of ca. $20 \mathrm{kDa}$ ) composed of PEG and either $\mathrm{Ala}_{4}$ or Ala ${ }_{6}$ peptides. Films cast from 40 wt\% HFIP solution of the polymer containing the Ala 4 tetrapeptide had better mechanical properties (tensile modulus ca. $310 \mathrm{MPa}$, tensile strength ca. $17 \mathrm{MPa}$, elongation at break ca. $26 \%$ ) than those of the equivalent polymer containing the GlyAlaGlyAla tetrapeptide. Increasing the length of the poly(alanine) stretch to six amino acids improved the tensile modulus and tensile strength to ca. 490 and 19 MPa respectively, yet decreased the elongation at break to $12 \%$. $\beta$-sheet rich fibres with $\mu \mathrm{m}$ scale diameters were prepared by extrusion of 5-15 wt\% HFIP solutions into a methanol-acetone coagulant bath (a process known as wetspinning) the elongation at break of such fibres were similar to natural silks, yet their tensile strengths (ca. $14 \mathrm{MPa}$ ) were much poorer than natural silk [15].

The high strength and directionality of hydrogen bonding interactions in organic solvents can be used to direct the self-assembly of molecules into supramolecular polymers. For example, conjugation of alkyl chains to the termini of the GlyAlaGlyAla tetrapeptide, yielded molecules that form supramolecular polymers in organic solvents (such as acetonitrile or toluene). The 
supramolecular polymer nanofibrils (of less than $20 \mathrm{~nm}$ ) hierarchically assembled into bundles (with widths of ca. $100 \mathrm{~nm}$ ) and subsequently into entangled networks of fibres with lengths of several micrometers, ultimately resulting in gelation of the solvent [16]. Alternatively, conjugation of the GlyAlaGlyAlaGly pentapeptide to either one or both termini of an oligothiophene (4-mer) yielded molecules that form supramolecular polymers in organic solvents (such as dichloromethane) that may have interesting nanoelectronic applications $[17,18]$.

\section{Silk-inspired proteins}

Although solid phase synthesis would theoretically allow the preparation of proteins with accurate primary sequences, the high molecular weights of naturally occurring silk proteins ( $M W>100 \mathrm{kDa}$ ) make this approach impractical. In contrast, fermentation of recombinantly 'engineered' silks is a more practical approach due to its potential for large scale production of proteins with precisely designed primary sequences, potentially allowing production of proteins incorporating entirely new functionality (bioactivity, catalytic properties etc...).

$\operatorname{Poly}(\mathrm{AlaGly})_{64}$, poly(AlaGly $)_{240}$ and poly([AlaGly $]_{3-6}$ GluGly) were produced by high cell density fermentation of recombinant $E$. coli in yields of up to $1 \mathrm{~g}$ per liter. Solutions of the proteins in formic acid formed gels upon dilution with water (to a $70 \%$ formic acid solution) and washing the gels with methanol yielded a $\beta$-sheet rich powder [19-21]. Hydrophobic derivatives of the analogous poly $\left([\text { GlyAla }]_{3}\right.$ GlyXaa) (e.g. Xaa = phenylalanine) were insoluble in water even in strongly denaturing conditions, whereas those with polar or charged residues (e.g. Xaa = tyrosine or lysine) could be dissolved in aqueous solutions of denaturants and were found to remain soluble after dialysis against $\mathrm{pH}$ buffered water, allowing their subsequent chemical modification. The assembly properties of the glutamic acid derivatives were demonstrated to be $\mathrm{pH}$ responsive, aggregating swiftly due to hydrophobic interactions upon protonation of the glutamic acids. Moreover, 
adsorption of amphiphilic derivatives ([GlyAla $]_{3}$ GlyGlu[GlyAla $]_{3}$ GlyLys) ${ }_{28}$ to surfaces was shown to render hydrophobic surfaces hydrophilic, and hydrophilic surfaces hydrophobic [19, 22, 23].

While a number of research groups have prepared spider silk-inspired proteins, we are particularly interested in the production of proteins based upon the consensus sequences of the major ampullate silks of Araneus diadematus spiders (ADF-3 and ADF-4) that contain $\beta$-sheet forming blocks of Ala or Ala $_{8}$ and are known as eADF-3 and eADF-4 respectively [24]. Our proteins (of between 46 and $106 \mathrm{kDa}$ ) can be produced in high yield by high density fermentation in $E$. coli (or other suitable hosts such as yeast) and purified without the need for chromatographic separation which can be expensive and time consuming [25-27]. Our proteins are soluble in a variety of aqueous and non-aqueous solvents, which facilitates their processing into several different materials morphologies [1] including: fibres [28], films [29-32], foams [33], gels [34], capsules [35, 36] and spheres [37-39]. We have shown that the non-repetitive peptide sequence at the Carboxy-terminus of the proteins encourages their self-assembly [27], and that materials composed of blends of our proteins have improved materials properties [30]. We have shown our materials to be biodegradable [35] and furthermore demonstrated the ability to chemically modify our proteins, allowing us to either reinforce our materials by cross-linking [34], or impart novel functionality via immobilisation of bioactive moieties such as enzymes [32].

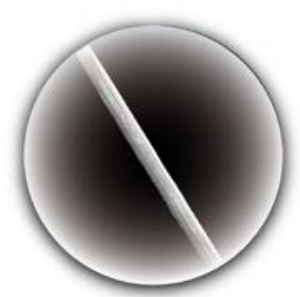

fiber

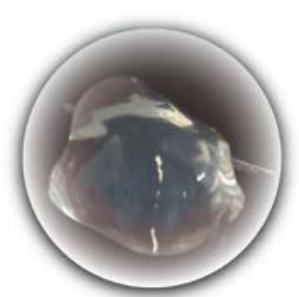

hydrogel

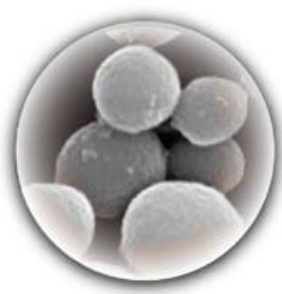

sphere

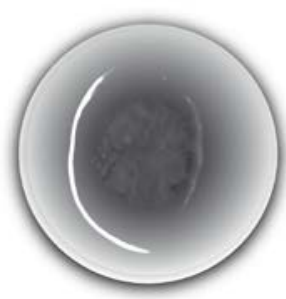

capsule

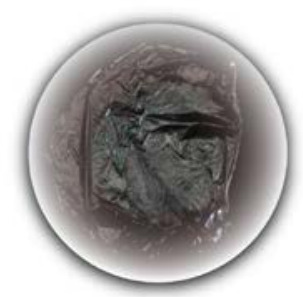

film

Figure 2. Examples of various materials morphologies preparable with silk-inspired polymers and proteins 


\section{Triggered assembly of silk-inspired polymers/proteins}

Natural silk proteins can be stored at high concentrations without the onset of undesirable aggregation inside the silkworm or spider. When necessary the silkworm or spider exposes the proteins to chemical and mechanical stimuli triggering protein assembly into fibres in a precisely controlled manner [28]. In vitro, self-assembly of silk-inspired polymers/proteins due to the formation of $\beta$-sheets is typically induced by exposure to a solvent such as an aqueous solution of potassium phosphate known to salt out the protein (as occurs during the natural spinning process) $[28,37,39]$ or methanol which dehydrates the $\beta$-sheet forming peptides within the polymer/protein [29]. Other stimuli such as stretching (mimicking post-spin draw applied by spiders) [40], storage [41], heat [42] or ultra-violet radiation [41] have also been shown to induce $\beta$-sheet assembly.

An alternative to this is self-assembly triggered by exposure to chemical stimuli that subsequently lead to a change of the chemical structure of the polymer/protein. For example as-synthesised silkinspired triblock copolymers (composed of methyl methacrylate and tert-butoxycarbonylAlaGlyAlaGly-ethyl methacrylate) had no well-defined secondary structure, as the tertbutoxycarbonyl group acted as a steric barrier to $\beta$-sheet formation, exposure of the polymers to trifluoroacetic acid led to acid catalysed deprotection of the tert-butoxycarbonyl group allowing the formation of $\beta$-sheets $[5,43]$. Proteins incorporating methionine residues near the $\beta$-sheet forming Ala 5 peptides were demonstrated to assemble in solution into nanofibrils due to $\beta$-sheet formation. Oxidation of the methionine residues to sulfoxides disrupted the $\beta$-sheets yielding fully soluble protein; and reduction of the oxidised residues triggered $\beta$-sheet formation and protein-assembly [44-46].

Another alternative is self-assembly triggered by exposure to biological stimuli such as enzymes. This principle was first proven with proteins incorporating phosphorylation sites near the $\beta$-sheet forming 
Ala 5 peptides. Phosphorylation of the serine residues (with cyclic adenosine monophosphate dependent kinase) yielded highly soluble protein, and subsequent dephosphorylation (with calf intestinal alkaline phosphatase) triggered $\beta$-sheet formation and protein-assembly [46-48]. Subsequently, short proteins incorporating the consensus repeats of the major ampullate silks of Euprosthenops australis spiders (containing long stretches of poly(alanine) [ $\left.\mathrm{Ala}_{12}-\mathrm{Ala}_{15}\right]$ that are highly prone to aggregation), the non-repetitive Carboxy-terminus from Nephila clavipes spiders (which we have previously shown to play a proactive role in silk protein assembly processes) and thioredoxin (a solubility enhancing fusion protein which prevents assembly of the proteins in solution) were prepared. Proteolytic cleavage of thioredoxin with thrombin triggered the assembly of $\beta$-sheet-rich fibres that were hundreds of centimetres in length and had $\mu \mathrm{m}$ scale diameters [49].

\section{Silk-based protein chimeras/hybrids}

A variety of silk-based chimeric/hybrid proteins have been produced in the hope of generating proteins incorporating the attractive properties of both proteins, leading to proteins with enhanced solubility, improved cell adhesion or capable of inducing biomineralisation.

Natural Samia cynthia ricini silk (whilst biocompatible and biodegradable) is virtually insoluble in both aqueous and non-aqueous solvents (due to repetitive stretches of $\mathrm{Ala}_{12-13}$ ) and therefore difficult to process into materials. Hybrid proteins (MWs between 17-36 kDa) based upon Samia cynthia ricini and Bombyx mori fibroins were sufficiently soluble to be able to process the resulting protein into fibres [50,51]. Natural elastins (present in connective tissues) tend to be highly insoluble, rendering processing into materials a challenge. Hybrid proteins (MWs between $45-85$ kDa) incorporating silk-like (GlyAlaGlyAlaGlySer) and elastin-like (GlyValGlyValPro) blocks are soluble in a variety of solvents facilitating their processing into fibres, films and gels, that are potentially suitable for various biomedical applications [52]. 
Hybrid proteins combining $\beta$-sheet forming peptide sequences (of either Bombyx mori or Samia cynthia ricini fibroins) and cell adhesive peptide sequences (such as the ArgGlyAsp (RGD) peptide sequence of fibronectin) were processable into fibres (with either $\mu \mathrm{m}$ or $\mathrm{nm}$ scale diameters) or films. In vitro cell-adhesion studies demonstrated markedly improved cell adhesion over natural silk proteins with mouse fibroblast [BALB/3T3] cells, human dermal fibroblast [NHDF] cells or African green monkey kidney [VERO] cells [53-56]. Incorporation of the RGD sequence into engineered proteins based upon Nephila clavipes spider dragline silk was subsequently shown to improve cell adhesion of mouse osteoblast MC3T3-E1 cells [57].

Hybrid proteins based upon the combination of Nephila clavipes spider dragline silk and the R5 peptide (which is derived from the repetitive motif found in silaffin proteins that are involved in silica formation at neutral pH in in vitro studies) were processed into fibres or films. Incubation of these materials with a water soluble silicon species led to biomineralisation of their surface [58]. Likewise, chimeric proteins based upon Nephila clavipes spider dragline silk and dentin matrix protein 1 (which is involved in the nucleation and oriented crystallisation of hydroxyapatite) could be processed into films. Incubation of the films in simulated body fluid led to the growth of hydroxyapatite crystals on their surface, whereas silk films without the dentin matrix protein 1 domain did not induce biomineralisation [59].

\section{Conclusions}

We are convinced that the production of silk-inspired polymers/proteins aid fundamental research of natural self-assembly processes of silk proteins, and has significant potential for technological and biomedical applications. We envisage that in the future de novo designed proteins inspired by silks will have a significant positive impact upon our daily lives. 


\section{Acknowledgements}

JGH gratefully acknowledges financial support from the Alexander von Humboldt Foundation, and TS acknowledges financial support from Army Research Office (W911NF-0810284).

\section{References}

1 Hardy, J. G., Römer, L. and Scheibel, T. (2008) Polymeric materials based on silk proteins. Polymer. 49, 4309-4327

2 Scheibel, T. (2005) Protein fibers as performance proteins: new technologies and applications. Current Opinion in Biotechnology. 16, 427-433

3 Scheibel, T. (2004) Spider silks: recombinant synthesis, assembly, spinning, and engineering of synthetic proteins. Microbial Cell Factories. 3, 14

4 Sponner, A., Vater, W., Monajembashi, S., Unger, R. E., Grosse, F. and Wiesshart, K. (2007) Composition and Hierarchical Organisation of a Spider Silk. PLoS ONE. 2, e998

5 Smeenk, J. M., Ayres, L., Stunnenberg, H. G. and van Hest, J. C. M. (2005) Polymer protein hybrids. Macromolecular Symposia. 225, 1-8

6 Smeenk, J. M., Otten, M. B. J., Thies, J., Tirrell, D. A., Stunnenberg, H. G. and van Hest, J. C. M. (2005) Controlled Assembly of Macromolecular $\beta$-sheet Fibrils. Angewandte Chemie-International Edition. 44, 1968-1971

7 Smeenk, J. M., Schoen, P., Otten, M. B. J., Speller, S., Stunnenberg, H. G. and van Hest, J. C. M. (2006) Fibril Formation by Triblock Copolymers of Silklike $\beta$-sheet Polypeptides and Poly(ethylene glycol). Macromolecules. 39, 2989-2997

8 Zhou, C. C., Leng, B. X., Yao, J. R., Qian, J., Chen, X., Zhou, P., Knight, D. P. and Shao, Z. Z. (2006) Synthesis and characterization of multiblock copolymers based on spider dragline silk proteins. Biomacromolecules. 7, 2415-2419

9 Chen, Z. M., Kimura, M., Suzuki, M., Kondo, Y., Hanabusa, K. and Shirai, H. (2003) Synthesis and characterization of new acrylic polymer containing silk protein. Sen-I Gakkaishi. 59, 168-172 10 Chen, Z. M., Kimura, M., Suzuki, M., Tsuiki, H., Kondo, Y., Hanabusa, K. and Shirai, H. (2004) Preparation of $\mathrm{Zn}(\mathrm{II})$-poly(acrylonitrile-co-silk fibroin peptide) complexes: Their odor-removal and antibacterial activities. Sen-I Gakkaishi. 60, 81-87

11 Chen, Z. M., Suzuki, M., Kimura, M., Kondo, Y., Hanabusa, K. and Shirai, H. (2004) Synthesis and characterization of spinning poly(acrylonitrile-co-silk fibroin peptide)s. Journal of Applied Polymer Science. 92, 1540-1547

12 Winningham, M. J. and Sogah, D. Y. (1997) A Modular Approach to Polymer Architecture Control via Catenation of Prefabricated Biomolecular Segments: Polymers Containing Parallel $\beta$ sheets Templated by a Phenoxathiin Reverse Turn Mimic. Macromolecules. 30, 862-876 13 Rathore, O., Winningham, M. J. and Sogah, D. Y. (2000) A novel silk-based segmented block copolymer containing GlyAlaGlyAla $\beta$-sheets templated by phenoxathiin. Journal of Polymer Science Part a-Polymer Chemistry. 38, 352-366

14 Rathore, O. and Sogah, D. Y. (2001) Nanostructure formation through $\beta$-sheet self-assembly in silk-based materials. Macromolecules. 34, 1477-1486

15 Rathore, O. and Sogah, D. Y. (2001) Self-assembly of $\beta$-sheets into nanostructures by poly(alanine) segments incorporated in multiblock copolymers inspired by spider silk. Journal of the American Chemical Society. 123, 5231-5239 
16 Escuder, B. and Miravet, J. F. (2006) Silk-Inspired Low-Molecular-Weight Organogelator. Langmuir. 22, 7793-7797

17 Gus'kova, O. A., Khalatur, P. G., Bauerle, P. and Khokhlov, A. R. (2008) Silk-inspired 'molecular chimeras': Atomistic simulation of nanoarchitectures based on thiophene-peptide copolymers. Chemical Physics Letters. 461, 64-70

18 Klok, H. A., Rosler, A., Gotz, G., Mena-Osteritz, E. and Bauerle, P. (2004) Synthesis of a silkinspired peptide oligothiophene conjugate. Organic \& Biomolecular Chemistry. 2, 3541-3544

19 Krejchi, M. T., Atkins, E. D. T., Waddon, A. J., Fournier, M. J., Mason, T. L. and Tirrell, D. A. (1994) Chemical Sequence Control of $\beta$-sheet Assembly in Macromolecular Crystals of Periodic Polypeptides. Science. 265, 1427-1432

20 Krejchi, M. T., Cooper, S. J., Deguchi, Y., Atkins, E. D. T., Fournier, M. J., Mason, T. L. and Tirrell, D. A. (1997) Crystal Structures of Chain-Folded Antiparallel $\beta$-sheet Assemblies from Sequence-Designed Periodic Polypeptides. Macromolecules. 30, 5012-5024

21 Panitch, A., Matsuki, K., Cantor, E. J., Cooper, S. J., Atkins, E. D. T., Fournier, M. J., Mason, T. L. and Tirrell, D. A. (1997) Poly(L-alanylglycine): Multigram-Scale Biosynthesis, Crystallization, and Structural Analysis of Chain-Folded Lamellae. Macromolecules. 30, 42-49

22 Higashiya, S., Topilina, N. I., Ngo, S. C., Zagorevskii, D. and Welch, J. T. (2007) Design and Preparation of $\beta$-sheet Forming Repetitive and Block-Copolymerised Polypeptides.

Biomacromolecules. 8, 1487-1497

23 Werten, M. W. T., Moers, A. P. H. A., Vong, T., Zuilhof, H., Van Hest, J. C. M. and de Wolf, F. A. (2008) Biosynthesis of an Amphiphilic Silk-Like Polymer. Biomacromolecules. 9, 1705-1711

24 Vendrely, C. and Scheibel, T. (2007) Biotechnological production of spider-silk proteins enables new applications. Macromolecular Bioscience. 7, 401-409

25 Schmidt, M., Römer, L., Strehle, M. and Scheibel, T. (2007) Conquering isoleucine auxotrophy of Escherichia coli BLR(DE3) to recombinantly produce spider silk proteins in minimal media. Biotechnology Letters. 29, 1741-1744

26 Huemmerich, D., Scheibel, T., Vollrath, F., Cohen, S., Gat, U. and Ittah, S. (2004) Novel assembly properties of recombinant spider dragline silk proteins. Current Biology. 14, 2070-2074 27 Huemmerich, D., Helsen, C. W., Quedzuweit, S., Oschmann, J., Rudolph, R. and Scheibel, T. (2004) Primary structure elements of spider dragline silks and their contribution to protein solubility. Biochemistry. 43, 13604-13612

28 Rammensee, S., Slotta, U., Scheibel, T. and Bausch, A. R. (2008) Assembly mechanism of recombinant spider silk proteins. Proceedings of the National Academy of Sciences of the United States of America. 105, 6590-6595

29 Metwalli, E., Slotta, U., Darko, C., Roth, S. V., Scheibel, T. and Papadakis, C. M. (2007) Structural changes of thin films from recombinant spider silk proteins upon post-treatment. Applied Physics a-Materials Science \& Processing. 89, 655-661

30 Slotta, U., Tammer, M., Kremer, F., Koelsch, P. and Scheibel, T. (2006) Structural analysis of spider silk films. Supramolecular Chemistry. 18, 465-471

31 Junghans, F., Morawietz, M., Conrad, U., Scheibel, T., Heilmann, A. and Spohn, U. (2006) Preparation and mechanical properties of layers made of recombinant spider silk proteins and silk from silk worm. Applied Physics a-Materials Science \& Processing. 82, 253-260

32 Huemmerich, D., Slotta, U. and Scheibel, T. (2006) Processing and modification of films made from recombinant spider silk proteins. Applied Physics a-Materials Science \& Processing. 82, 219-222 33 Römer, L. and Scheibel, T. (2007) Basis for new material - Spider silk protein. Chemie in Unserer Zeit. 41, 306-314

34 Rammensee, S., Huemmerich, D., Hermanson, K. D., Scheibel, T. and Bausch, A. R. (2006) Rheological characterization of hydrogels formed by recombinantly produced spider silk. Applied Physics a-Materials Science \& Processing. 82, 261-264

35 Hermanson, K. D., Huemmerich, D., Scheibel, T. and Bausch, A. R. (2007) Engineered microcapsules fabricated from reconstituted spider silk. Advanced Materials. 19, 1810-1815 
36 Hermanson, K. D., Harasim, M. B., Scheibel, T. and Bausch, A. R. (2007) Permeability of silk microcapsules made by the interfacial adsorption of protein. Physical Chemistry Chemical Physics. 9, 6442-6446

37 Slotta, U. K., Rammensee, S., Gorb, S. and Scheibel, T. (2008) An Engineered Spider Silk Protein Forms Microspheres. Angewandte Chemie-International Edition. 47, 4592-4594

38 Liebmann, L., Hummerich, D., Scheibel, T. and Fehr, M. (2008) Formulation of poorly watersoluble substances using a self-assembling spider silk protein. Colloids and Surfaces aPhysicochemical and Engineering Aspects. 331, 126-132.

39 Lammel, A., Schwab, M., Slotta, U., Winter, G. and Scheibel, T. (2008) Processing conditions for the Formation of Spider Silk Microspheres. ChemSusChem. 1, 413-416

40 Demura, M. and Asakura, T. (1989) Immobilization of Glucose-Oxidase with Bombyx-Mori Silk Fibroin by Only Stretching Treatment and Its Application to Glucose Sensor. Biotechnology and Bioengineering. 33, 598-603

41 Bhat, N. V. and Ahirrao, S. M. (1983) Investigation of the Structure of Silk Film Regenerated with Lithium Thiocyanate Solution. Journal of Polymer Science Part a-Polymer Chemistry. 21, 12731280

42 Magoshi, J. and Nakamura, S. (1975) Studies on Physical-Properties and Structure of Silk Glass-Transition and Crystallization of Silk Fibroin. Journal of Applied Polymer Science. 19, 1013-1015 43 Ayres, L., Adams, P. H. H. M., Lowik, D. W. P. M. and van Hest, J. C. M. (2005) $\beta$-sheet side chain polymers synthesized by atom-transfer radical polymerization. Biomacromolecules. 6, 825-831 44 Szela, S., Avtges, P., Valluzzi, R., Winkler, S., Wilson, D., Kirschner, D. and Kaplan, D. L. (2000) Reduction-oxidation control of $\beta$-sheet assembly in genetically engineered silk. Biomacromolecules. 1, 534-542

45 Valluzzi, R., Szela, S., Avtges, P., Kirschner, D. and Kaplan, D. (1999) Methionine redox controlled crystallization of biosynthetic silk spidroin. Journal of Physical Chemistry B. 103, 1138211392

46 Winkler, S., Szela, S., Avtges, P., Valluzzi, R., Kirschner, D. A. and Kaplan, D. (1999) Designing recombinant spider silk proteins to control assembly. International Journal of Biological Macromolecules. 24, 265-270

47 Winkler, S., Wilson, D. and Kaplan, D. L. (2000) Controlling $\beta$-sheet assembly in genetically engineered silk by enzymatic phosphorylation/dephosphorylation (vol 39, pg 12739, 2000). Biochemistry. 39, 14002-14002

48 Winkler, S., Wilson, D. and Kaplan, D. L. (2000) Controlling $\beta$-sheet assembly in genetically engineered silk by enzymatic phosphorylation/dephosphorylation. Biochemistry. 39, 12739-12746 49 Stark, M., Grip, S., Rising, A., Hedhammar, M., Engstrom, W., Hjalm, G. and Johansson, J. (2007) Macroscopic fibers self-assembled from recombinant miniature spider silk proteins. Biomacromolecules. 8, 1695-1701

50 Asakura, T., Nitta, K., Yang, M. Y., Yao, J. M., Nakazawa, Y. and Kaplan, D. L. (2003) Synthesis and characterization of chimeric silkworm silk. Biomacromolecules. 4, 815-820

51 Yang, M. Y. and Asakura, T. (2005) Design, expression and solid-state NMR characterization of silk-like materials constructed from sequences of spider silk, Samia cynthia ricini and Bombyx mori silk fibroins. Journal of Biochemistry. 137, 721-729

52 Megeed, Z., Cappello, J. and Ghandehari, H. (2002) Genetically engineered silk-elastinlike protein polymers for controlled drug delivery. Advanced Drug Delivery Reviews. 54, 1075-1091 53 Asakura, T., Tanaka, C., Yang, M. Y., Yao, J. M. and Kurokawa, M. (2004) Production and characterization of a silk-like hybrid protein, based on the polyalanine region of Samia cynthia ricini silk fibroin and a cell adhesive region derived from fibronectin. Biomaterials. 25, 617-624

54 Yanagisawa, S., Zhu, Z. H., Kobayashi, I., Uchino, K., Tamada, Y., Tamura, T. and Asakura, T. (2007) Improving cell-adhesive properties of recombinant Bombyx mori silk by incorporation of collagen or fibronectin derived peptides produced by transgenic silkworms. Biomacromolecules. 8, 3487-3492 
55 Yang, M., Yamauchi, K., Kurokawa, M. and Asakura, T. (2007) Design of silk-like biomaterials inspired by mussel-adhesive protein. Tissue Engineering. 13, 2941-2947

56 Yang, M., Tanaka, C., Yamauchi, K., Ohgo, K., Kurokawa, M. and Asakura, T. (2008) Silklike materials constructed from sequences of Bombyx mori silk fibroin, fibronectin, and elastin. Journal of Biomedical Materials Research Part A. 84A, 353-363

57 Morgan, A. W., Roskov, K. E., Lin-Gobson, S., Kaplan, D. L., Becker, M. L. and Simon, C. G. (2008) Characterization and optimization of RGD-containing silk blends to support osteoblastic differentiation. Biomaterials. 29, 2556-2563

58 Foo, C. W. P., Patwardhan, S. V., Belton, D. J., Kitchel, B., Anastasiades, D., Huang, J., Naik, R. R., Perry, C. C. and Kaplan, D. L. (2006) Novel nanocomposites from spider silk-silica fusion (chimeric) proteins. Proceedings of the National Academy of Sciences of the United States of America. 103, 9428-9433

59 Huang, J., Wong, C., George, A. and Kaplan, D. L. (2007) The effect of genetically engineered spider silk-dentin matrix protein 1 chimeric protein on hydroxyapatite nucleation. Biomaterials. 28, 2358-2367 